\title{
A!
}

This is an electronic reprint of the original article.

This reprint may differ from the original in pagination and typographic detail.

See, Erich Michael; Tossi, Camilla; Hällström, Lassi; Tittonen, Ilkka

\section{Photodeposition of RuOx Nanostructures on TiO2 Films with a Controllable Morphology}

\section{Published in:}

ACS Omega

DOI:

10.1021/acsomega.9b04077

Published: 19/05/2020

Document Version

Publisher's PDF, also known as Version of record

Published under the following license:

Other

Please cite the original version:

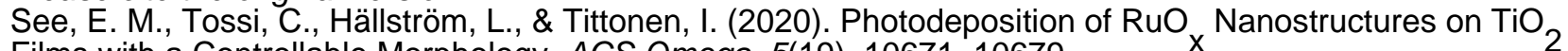
Films with a Controllable Morphology. ACS Omega, 5(19), 10671-10679.

https://doi.org/10.1021/acsomega.9b04077

This material is protected by copyright and other intellectual property rights, and duplication or sale of all or part of any of the repository collections is not permitted, except that material may be duplicated by you for your research use or educational purposes in electronic or print form. You must obtain permission for any other use. Electronic or print copies may not be offered, whether for sale or otherwise to anyone who is not an authorised user. 


\title{
Photodeposition of $\mathrm{RuO}_{x}$ Nanostructures on $\mathrm{TiO}_{2}$ Films with a Controllable Morphology
}

\author{
Erich Michael See,* Camilla Tossi, Lassi Hällström, and Ilkka Tittonen
}

Cite This: ACS Omega 2020, 5, 10671-10679

Read Online

ABSTRACT: $\mathrm{RuO}_{2} / \mathrm{TiO}_{2}$ catalysts have shown broad use in promoting a variety of photocatalytic phenomena, such as water splitting and the photodecomposition of organic dyes and pollutants. Most current methods of photodepositing ruthenium oxide species $\left(\mathrm{RuO}_{x}\right)$ onto titanium dioxide $\left(\mathrm{TiO}_{2}\right)$ films involve precursors that are either difficult to produce and prone to decomposition, such as $\mathrm{RuO}_{4}$, or require high-temperature oxidations, which can reduce the quality of the resulting catalyst and increase the risks and toxicity of the procedure. The present work demonstrates the photodeposition of $\mathrm{RuO}_{x}$ onto $\mathrm{TiO}_{2}$ films, using potassium perruthenate

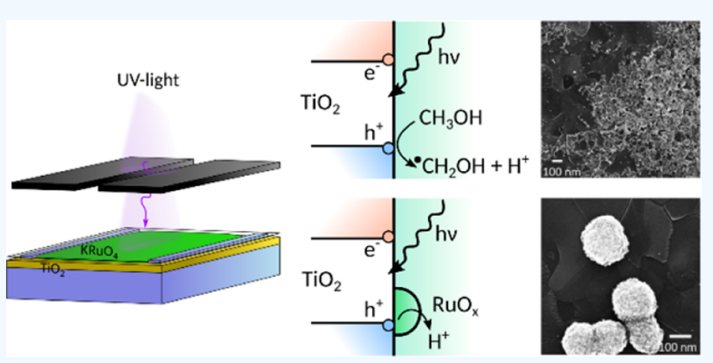
$\left(\mathrm{KRuO}_{4}\right)$ as a precursor, by improving substantially a procedure known to work on $\mathrm{TiO}_{2}$ nanopowders. In addition to demonstrating the applicability of this method of photodeposition to $\mathrm{TiO}_{2}$ films, this work also explores the importance of the material phase of the $\mathrm{TiO}_{2}$ substrate, outlines viable concentrations and photodeposition times at a given optical intensity, and demonstrates that the morphology of the photodeposited nanostructures changes from cauliflower-like spheroids to a matted, porous sponge-like structure with the addition of methanol to the precursor solution. This morphology change has not been documented previously. By providing an explanation for this difference in the morphology, this work provides both newer insights into the photodeposition process and provides an excellent foundation for future procedures, allowing a more targeted and controlled deposition based on the desired morphology.

\section{INTRODUCTION}

In recent years, catalytic nanoparticles made of materials including platinum, gold, indium, and manganese have been used to greatly improve the efficiency and ability of photocatalytic materials, such as titanium dioxide $\left(\mathrm{TiO}_{2}\right){ }^{1}$ $\mathrm{TiO}_{2}$ is attractive on its own because of its low cost, low toxicity, ${ }^{2}$ and general stability. ${ }^{3}$ Further, $\mathrm{TiO}_{2}$ has a broad range of uses without modification, which include water splitting $^{4}$ and the catalytic removal of various pollutants. ${ }^{5-7}$

Although $\mathrm{TiO}_{2}$ has a broad band gap ${ }^{8,9}$ and high chargecarrier recombination rate, ${ }^{10}$ the impact of these properties can be minimized by the addition of metallic and semiconductor cocatalysts through effects such as boosting the separation and translation of charge carriers within the composite catalyst ${ }^{11-13}$ or by effectively narrowing the band gap of the material and increasing the probability of photoactivation. ${ }^{14}$ This results in improvements such as lowering the activation energy of the catalysis, ${ }^{15}$ suppressing photocorrosion, ${ }^{12}$ enhancing charge separation, ${ }^{12}$ and in the case of noble metal cocatalysts, providing plasmonic photocatalytic enhancement. ${ }^{16}$

Ruthenium(IV) oxide $\left(\mathrm{RuO}_{2}\right)$ has shown significant promise as the cocatalyst with $\mathrm{TiO}_{2}$ because of its synergy with the bandgap of $\mathrm{TiO}_{2}{ }^{14}$ Hybrid $\mathrm{RuO}_{2} / \mathrm{TiO}_{2}$ catalysts have been demonstrated to promote catalytic phenomena such as the production of hydrogen by photoreforming and water splitting $^{17,18}$ and the photodecomposition of organic dyes. ${ }^{19}$ When deposited on a $\mathrm{TiO}_{2}$ substrate, $\mathrm{RuO}_{2}$ is capable of serving as a catalyst on photovoltaic junctions, ${ }^{18}$ protecting $\mathrm{TiO}_{2}$ against corrosion, ${ }^{12}$ and acting as nucleation sites for carbon nanotube growth. ${ }^{20}$ For these reasons, the ability to selectively deposit $\mathrm{RuO}_{2}$ nanoparticles onto semiconductor substrates, such as $\mathrm{TiO}_{2}$, is still of significant interest. However, many of the methods of depositing $\mathrm{RuO}_{2}$ onto $\mathrm{TiO}_{2}$ surfaces involve toxic precursors, such as $\mathrm{RuCl}_{3}$ or $\mathrm{RuO}_{4}$, which is both highly toxic and unstable at room temperature. ${ }^{21}$

Potassium perruthenate $\left(\mathrm{KRuO}_{4}\right)$ has shown appreciable promise as a less-toxic replacement for $\mathrm{RuCl}_{3}$. Previous work discussed a method for synthesizing a combined $\mathrm{RuO}_{2} / \mathrm{TiO}_{2}$ catalyst using an aqueous $\mathrm{KRuO}_{4}$ precursor solution and a Degussa P-25 titanium nanoparticle powder catalyst, which is a commercially available $\mathrm{TiO}_{2}$ nanopowder that contains both rutile and anatase phases. ${ }^{22}$ This photodeposition theoretically utilizes the following pathway

Received: November 30, 2019

Accepted: April 27, 2020

Published: May 7, 2020 


$$
\begin{aligned}
& 4 \mathrm{RuO}_{4}^{-}+4 \mathrm{H}^{+}+4 \mathrm{TiO}_{2} \\
& \stackrel{\mathrm{h} \nu}{\longrightarrow} 4 \mathrm{TiO}_{2} / \mathrm{RuO}_{2}+3 \mathrm{O}_{2}+2 \mathrm{H}_{2} \mathrm{O}
\end{aligned}
$$

Through this, the dissolved potassium perruthenate is reduced onto the $\mathrm{TiO}_{2}$ nanopowder to form a hybrid nanocatalyst. However, the effects of the crystallinity of the $\mathrm{TiO}_{2}$ nanopowder, the initial precursor concentrations used, and the presence or effect of hole scavengers, which are commonly used in such photodepositions, have not been thoroughly reported. Further, the process described is solely focused on the photodeposition of $\mathrm{RuO}_{x}$ onto a $\mathrm{TiO}_{2}$ nanopowder suspension and does not explore the parameters required for photodeposition onto a substrate.

Though other works have looked at the deposition of $\mathrm{RuO}_{x}$ onto a $\mathrm{TiO}_{2}$ substrate using $\mathrm{KRuO}_{4}$, they have utilized different techniques such as galvanostatic photodeposition ${ }^{18}$ or electrochemical anodization. ${ }^{23}$ These techniques may be impractical in the case of small samples or nonconducting sample substrates, as it may not always be feasible to fabricate electrical contacts onto small samples. The method put forward in this work, in contrast, is purely photodriven and does not require an external voltage source or current to be applied to the sample or solution. This allows it to be used in the absence of electrical contacts, which expands the types and morphologies of surfaces it can be deployed on and theoretically allows for better control of the deposited areas via techniques such as photomasking, should a specific catalyst loading be desired.

This work aims to examine and characterize the photodeposition of $\mathrm{KRuO}_{4}$ onto anatase and amorphous titanium dioxide substrates under comparable photodeposition conditions. This will provide a baseline for further study, including viable precursor concentrations and minimum photodeposition times at a given power. This work will also demonstrate that the presence or absence of a hole scavenger (methanol) completely alters the morphology of the photodeposited material, an effect which has not been previously described or explored in the literature. Primarily, the literature rarely mentions photodeposition that takes place even in the absence of a charge carrier scavenger or sacrificial reagents: this has been documented in literature only when arguing that the photodeposition of metals in the absence of a hole scavenger leads to the formation of oxides instead of metals. ${ }^{24-26}$ Indeed, in general, literature has rarely focused on the roles of scavengers ${ }^{27}$ and usually it reflects on the different morphologies only when comparing different techniques ${ }^{28}$ or different scavengers. ${ }^{27}$ By taking care to clearly spell out all steps and experimental parameters, this will provide a recipe that is straightforward to reproduce and is easily modified. This information will better allow future works to build off this safer, one-pot photodeposition process. Further, by demonstrating that the morphology can be controlled via the presence or absence of methanol, we provide a mechanism allowing future researchers and fabricators to better tailor the structure of the photodeposited $\mathrm{RuO}_{2}$ to suit their purposes.

\section{RESULTS}

A droplet $(150 \mu \mathrm{L})$ of a solution of $\mathrm{KRuO}_{4}(1 \mathrm{mM})$ was placed on a $\mathrm{TiO}_{2}$ substrate and then exposed under a photomask to UV light. Table 1 presents the list of samples and experimental conditions, each sample was fabricated under, including substrate crystallinity, methanol concentration, and photoexposure time.

Table 1. List of Samples, Outlining the Crystallinity of the Substrate, Exposure Time, and vol \% Methanol for Each Sample

\begin{tabular}{cccc} 
sample & $\mathrm{TiO}_{2}$ crystallinity & exposure time $(\mathrm{min})$ & \% vol methanol \\
$\mathrm{A}$ & anatase & 45 & 0 \\
$\mathrm{~B}$ & anatase & 30 & 0 \\
$\mathrm{C}$ & anatase & 15 & 0 \\
$\mathrm{D}$ & anatase & 5 & 0 \\
$\mathrm{E}$ & anatase & 45 & 10 \\
F & anatase & 30 & 10 \\
G & anatase & 15 & 10 \\
$\mathrm{H}$ & anatase & 5 & 10 \\
$\mathrm{I}$ & amorphous & 90 & 0 \\
$\mathrm{~J}$ & amorphous & 90 & 10 \\
\hline
\end{tabular}

Initial visual observation shows an immediate difference between exposed and unexposed areas on anatase samples with longer deposition times, samples A and F, shown in Supporting Information Figure S1. Further, there is a noticeable difference in the color of the photodeposited material on these two samples, indicating that the presence or absence of methanol has either changed the structure or the chemistry of the deposited material, allowing a quick quantitative check of the process. This is covered in more detail in the Supporting Information. Conversely, the samples exposed on amorphous $\mathrm{TiO}_{2}$, samples I and J, do not show any obvious signs of photodeposition. To further investigate these differences and characterize the results of the deposition attempt, SEM micrographs of the samples were taken, and to confirm the presence of $\mathrm{Ru}$ on the surface and to characterize the photodeposited structure, energy-dispersive X-ray spectroscopy (EDX) maps were generated, and X-ray photoelectron spectroscopy (XPS) measurements were performed. For ease of comprehension, we will present the samples without and with methanol in separate subsections.

2.1. Deposition without Methanol on Anatase $\mathrm{TiO}_{2}$. Overall, the deposition of $\mathrm{KRuO}_{4}$ onto anatase $\mathrm{TiO}_{2}$ in the absence of methanol showed the formation of discrete spheroidal, cauliflower-like $\mathrm{RuO}_{x}$ nanoparticles. Although some nonspecific growth was noticed in unexposed areas, a far greater particle density was seen in the photoexposed area. Additional analysis showed that the primary deposition was in the form of $\mathrm{RuO}_{2}$, specifically.

Figure 1a,b shows micrographs of the exposed and unexposed areas, respectively, of sample $A$, where the photodeposition took place in the absence of a hole scavenger (methanol) over a period of $45 \mathrm{~min}$. The exposed region (Figure 1a) clearly has larger and far more densely packed nanoparticles than the unexposed area (Figure $1 \mathrm{~b}$ ) and while some deposition does occur in the unexposed region, the deposition is far less dense, and the particles present are much smaller. Figure 1c is a closeup of the photoexposed region of the sample. This closer examination shows that the deposition has resulted in rough nanospheroids, with the larger particles varying from 90 to $250 \mathrm{~nm}$ in diameter. In several cases, two or more spheroids have merged together to form more oblong structures. A few small particles with a diameter of approximately $10 \mathrm{~nm}$ or smaller can also be observed. 

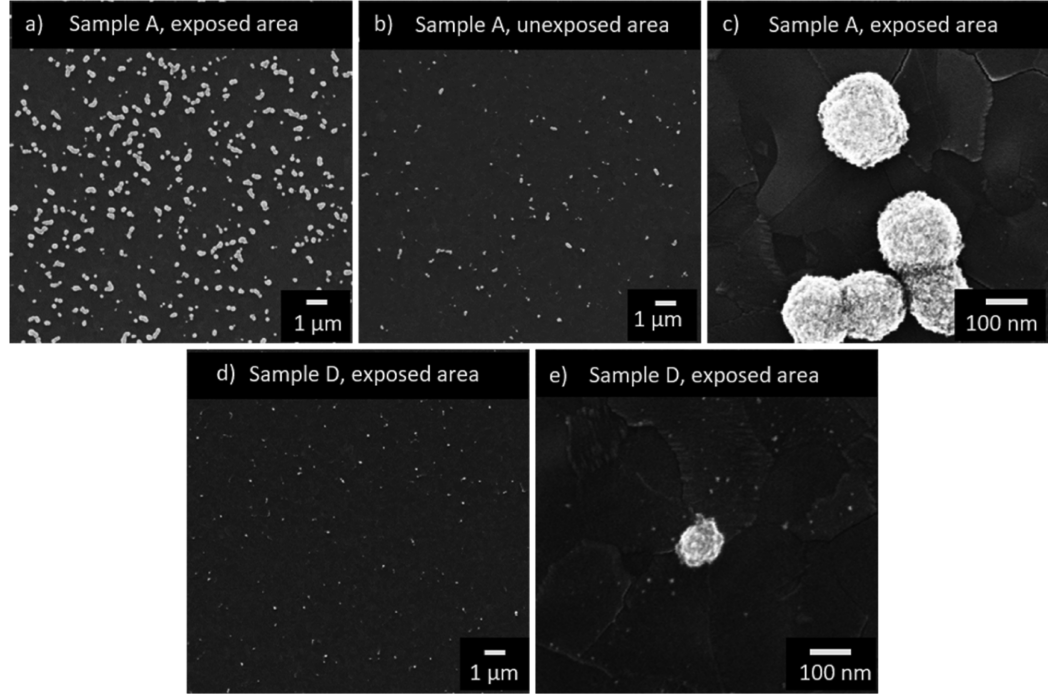

Figure 1. SEM micrographs of two samples photoexposed in the absence of methanol (samples A and D). (a) Photoexposed area on 45 min exposure sample (sample A). (b) Unexposed area on the 45 min exposure sample (sample A). (c) Closeup (200k $\times$ zoom) of large $\mathrm{RuO}_{x}$ particles in the photoexposed area of sample A. (d) Photoexposed area of sample with 5 min of photoexposure (sample D). (e) Closeup of photoexposed area on sample D.

Figure 1d,e shows micrographs of sample D, photoexposed for $5 \mathrm{~min}$ in the absence of methanol. The particles present are much smaller than those shown in Figure 1a-c (sample A), with the diameter of the larger spheres ranging from 60 to 95 $\mathrm{nm}$. Additionally, far fewer of these larger particles can be seen, placing a lower bound of $5 \mathrm{~min}$ on the photoexposure time needed to promote the photodeposition of several larger nanospheres at this optical power. A large quantity of the very small nanospheres are still visible in Figure 1e. Micrographs of samples B and C, with photoexposures of 30 and $15 \mathrm{~min}$, respectively, can be found in the Supporting Information Figure S2. The deposition on these samples is closer to that seen in sample A but with smaller spheres, suggesting that the sphere size increases with exposure time.

The occupied area (as a percentage of the total area), mean particle area, and mean particle diameter were calculated from atomic force microscopy (AFM) measurements (see Figure 2

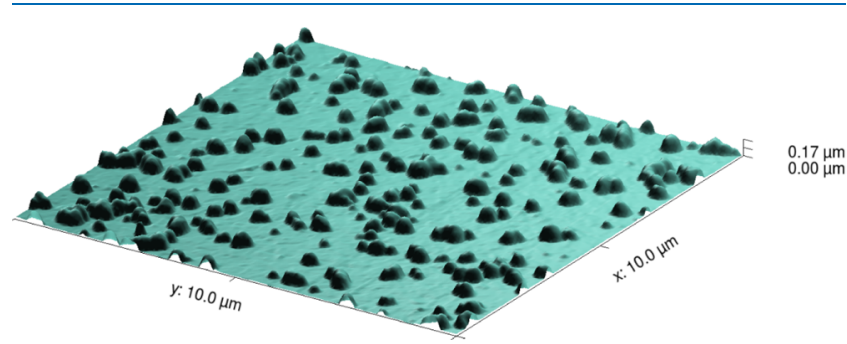

Figure 2. AFM map taken from the exposed area of sample A, used to calculate coverage and average particle size.

and Supporting Information Figure S3) and are listed in Table 2. With the exception of sample $C$, we can see a continuing trend of a smaller occupied area and smaller mean particle diameter as the exposure time decreases, which matches what we see in the SEM images.

EDX measurements of sample A reveal large quantities of silicon, along with $\mathrm{Ru}, \mathrm{Ti}, \mathrm{O}$, and N. Figure 3a shows an SEM image of sample A while Figures $3 b$ and $2 c$ show EDX maps for $\mathrm{Ru}$ and $\mathrm{O}$, in the same area. It can be seen that the areas of
Table 2. Size and Coverage Statistics of $\mathrm{RuO}_{x}$ Deposited in the Absence of Methanol

\begin{tabular}{ccccc} 
sample & $\begin{array}{c}\text { exposure } \\
\text { time }(\mathrm{min})\end{array}$ & $\begin{array}{c}\text { occupied } \\
\text { area }(\%)\end{array}$ & $\begin{array}{c}\text { Mean Particle } \\
\text { Area }\left(\mu \mathrm{m}^{2}\right)\end{array}$ & $\begin{array}{c}\text { mean particle } \\
\text { diameter }(\mathrm{nm})\end{array}$ \\
A & 45 & 14.75 & $84 \times 10^{-3}$ & 264 \\
B & 30 & 3.58 & $31.7 \times 10^{-3}$ & 163 \\
C & 15 & 6.63 & $40 \times 10^{-3}$ & 176 \\
D & 5 & 0.34 & $8.6 \times 10^{-3}$ & 87 \\
\hline
\end{tabular}
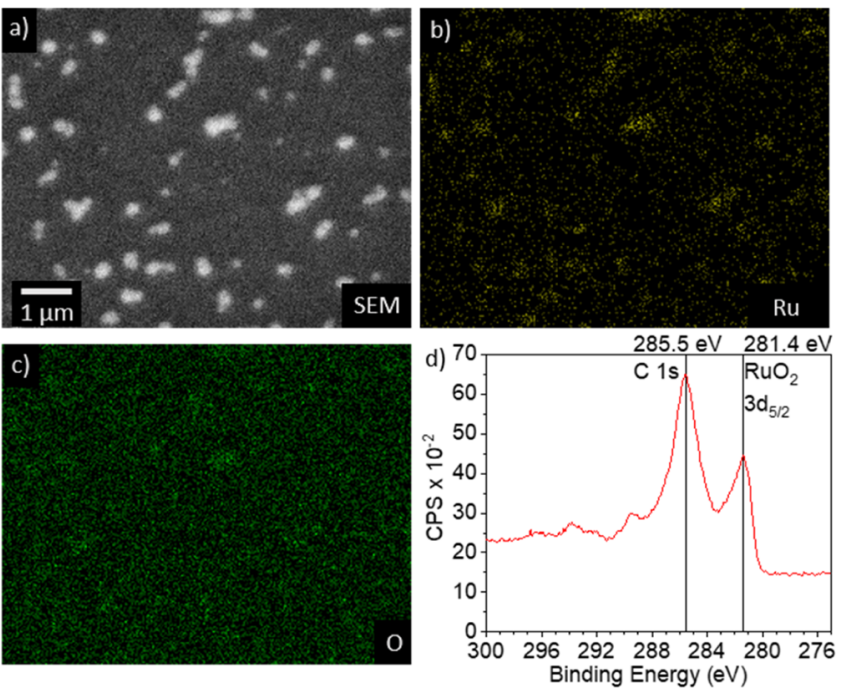

Figure 3. SEM image (a) and EDX maps of Ru (b) and $\mathrm{O}$ (c) for sample A, exposed without methanol for $45 \mathrm{~min}$. (d) XPS spectra of sample A, showing peaks corresponding to $\mathrm{RuO}_{2}$ and carbon.

high $\mathrm{Ru}$ density shown in Figure $3 \mathrm{~b}$ correspond to the larger nanoparticles seen in Figure 3a, confirming that the structures on the surface contain Ru. There is also some correlation in the EDX map for O (Figure 4c), though it is partially obscured by the oxygen in the $\mathrm{TiO}_{2}$ substrate.

To confirm the oxidation of the $\mathrm{Ru}$, we turn to XPS. Figure $3 \mathrm{~d}$ shows the C 1s XPS measurements of sample A. The peak 

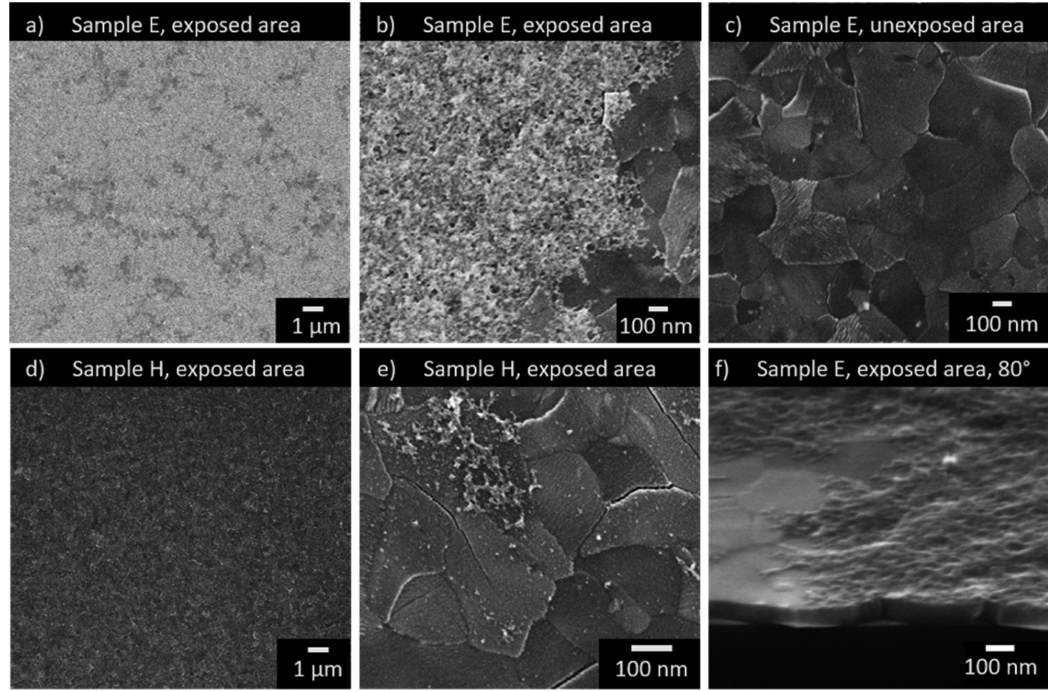

Figure 4. SEM micrographs of samples $\mathrm{E}$ and $\mathrm{H}$, photoexposed in a solution with $10 \%$ methanol content for 45 and 5 min, respectively (a) Photoexposed area of the $45 \mathrm{~min}$ photoexposure sample (sample E). (b) Closeup of $\mathrm{RuO}_{x}$ particles in the photoexposed area of sample E. (c) Closeup (100k× zoom) of the unexposed area of sample E. (d) Exposed area of sample photoexposed for 5 min (sample H). (e) Closeup of exposed area of sample H. (f) Edge-on image of the exposed area of sample E, taken at an $80^{\circ}$ angle.

at approximately $281.3 \mathrm{eV}$ in Figure $3 \mathrm{~d}$ corresponds to the mean $\mathrm{Ru}\left(3 \mathrm{~d}_{5 / 2}\right) \mathrm{RuO}_{2}$ peak and is not present in the $\mathrm{TiO}_{2}$ reference sample (Supporting Information Figure S4). ${ }^{29}$ This strongly indicates the presence of ruthenium in the $\mathrm{RuO}_{2}$ oxidation state.

2.2. Deposition with Methanol on Anatase $\mathrm{TiO}_{2}$. Overall, the deposition of $\mathrm{KRuO}_{4}$ onto anatase $\mathrm{TiO}_{2}$ in the presence of methanol showed the formation of a nearcontinuous sponge-like $\mathrm{RuO}_{x}$ structure. Although some minute-quantity nonspecific growth was noticed in unexposed areas, it was negligible compared to the deposition seen in exposed areas. Additional analysis showed that the primary deposition was in the form of $\mathrm{RuO}_{2}$, specifically.

Figure $3 \mathrm{a}, \mathrm{b}$ shows micrographs of the exposed areas of sample E, photoexposed for $45 \mathrm{~min}$ on anatase in the presence of a hole scavenger (methanol). The coverage and structure of the photodeposited $\mathrm{RuO}_{x}$ are completely different than that seen in Figure 1, forming a more porous, sponge-like structure, rather than an assortment of large nanospheres. These structures cover much of the available area, leaving little of the $\mathrm{TiO}_{2}$ substrate exposed. Closer inspection, shown in Figure $4 \mathrm{~b}$, makes the porous, sponge-like structure more apparent and also shows some of the same small particles seen in Figure 1c,e. Figure $4 \mathrm{c}$ shows the unexposed area of sample E, showing that there is almost no deposition of either morphology visible. This close examination does show some degree of nonspecific photodeposition in the form of tiny particles, but it is minute when compared to the deposition seen in the exposed areas.

Figure 4 d,e shows sample $\mathrm{H}$, photoexposed for $5 \mathrm{~min}$ in a $10 \%$ vol methanol solution. As with the photodeposition without methanol, shorter exposure times lead to less coverage, and very little can be seen in Figure 4d. Closer inspection, shown in Figure 4f, does reveal some structure growth, but there is very little, setting the necessary photodeposition size for generating larger structures, a lower bound of $5 \mathrm{~min}$ of photoexposure at this optical power. As in the samples without methanol, very small spheres can be seen in these images. Images of sample $F$ and sample $G$, exposed 30 and $15 \mathrm{~min}$, respectively, in a solution containing $10 \%$ methanol, can be found in Supporting Information Figure S5. They show less coverage than that seen in Figure $4 \mathrm{a}$ but far more than seen in Figure 4e.

Figure $4 \mathrm{f}$ shows a side-view of the growth region of sample E, selected so that both the $\mathrm{RuO}_{x}$ growth and $\mathrm{TiO}_{2}$ substrate are visible. When compared with the $40 \mathrm{~nm}$ thick $\mathrm{TiO}_{2}$ substrate, it is clear that the $\mathrm{RuO}_{x}$ layer is on the order of a few $n m$ thick. Similar images can be seen for sample F and sample G in the Supporting Information section (Supporting Information Figure S6).

Although sample E had a longer deposition time, sample G was chosen for EDX mapping because of having more areas where both $\mathrm{RuO}_{x}$ structures and bare $\mathrm{TiO}_{2}$ were present. Figure 5a shows an SEM image of the exposed area of sample $\mathrm{G}$ while Figure $5 \mathrm{~b}, \mathrm{c}$ shows the EDX maps for $\mathrm{Ru}$ and $\mathrm{O}$, respectively.

Given the sprawling nature of the photodeposited structure, the correlation in the EDX mapping is not as strong as in the case in Figure 4. Still, a correlation can be seen between the brightest spots on the left- and right-hand sides in Figure 5a and the denser ruthenium mapping shown in Figure $5 b$, indicating that the porous deposition is also $\mathrm{RuO}_{x}$. No clear correlation can be seen in the $\mathrm{O}$ map, and possible reasons for this are damage to the material from the EDX measurement, the thinness of the photo-deposited material, and the ubiquity of oxygen in the $\mathrm{TiO}_{2}$ substrate, or some combination of the three.

We can get a clearer picture of the oxygen content by turning, instead, to XPS. Figure 5d shows the C 1s XPS measurements for sample E. Figure $5 \mathrm{~d}$ is remarkably similar to Figure $3 \mathrm{~d}$, with the strong peak at $281.3 \mathrm{eV}$, confirming that a majority of the $\mathrm{Ru}$ deposited on the surface is likely in the $\mathrm{RuO}_{2}$ state. $^{29}$ Additionally, it can be seen that the peak at approximately $281.3 \mathrm{eV}$ is higher relative to the $286 \mathrm{eV}$ peak than in sample A (Figure 2d), which implies that there is a larger $\mathrm{RuO}_{2}$ content, or at least a much broader coverage, which is consistent with the images shown in Figure 4.

2.3. Deposition on Amorphous $\mathrm{TiO}_{2}$. In contrast to the above samples, relatively little photodeposition was found on 

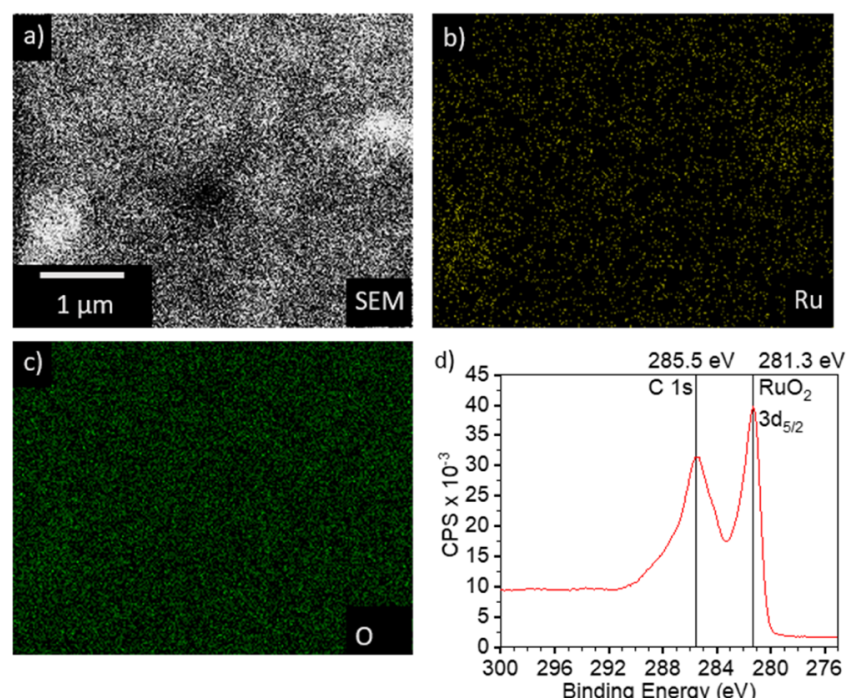

Figure 5. SEM image (a) and EDX maps of Ru (b) and O (c) on sample G (photoexposed for $15 \mathrm{~min}$ in a $10 \%$ by volume methanol solution). (d) XPS spectra of sample E, showing peaks corresponding to $\mathrm{RuO}_{2}$ and carbon.

samples using amorphous $\mathrm{TiO}_{2}$, even at exposure times of 90 min. Supporting Information Figure S7 is a representative micrograph of the exposed and unexposed areas of sample I, where the photoexposure took place on amorphous $\mathrm{TiO}_{2}$ in the absence of methanol. Although some very minor particle deposition can be seen, there is no clear difference between the exposed and unexposed areas, and when compared to samples on anatase with a third of the exposure time, no major evidence of photodeposition is present. Sample J, where the photodeposition took place on amorphous $\mathrm{TiO}_{2}$ in the presence of methanol, shows slightly better results, as seen in the Supporting Information Figure S8. Although a very minor degree of difference can be seen between the exposed and unexposed areas of the sample, very little deposition appears to have taken place, even with a photoexposure time double that used for sample E, shown in Figure $4 a$, which had an anatase substrate.

\section{DISCUSSION}

From the above results, we can determine that the quantity and morphology of the $\mathrm{RuO}_{x}$ depended on three major factors. The most obvious of these was the presence or absence of methanol, which heavily altered the morphology of the deposited material. The two other factors are the crystallinity of the $\mathrm{TiO}_{2}$ substrate (amorphous vs anatase), which determined whether the deposition could occur at all, and the photoexposure of the sample (time and exposed vs unexposed), which primarily determined the quantity of the deposited material. By examining each of these factors, we can both better understand the deposition process, convincingly demonstrate that this is a photodriven process, and expand how altering the variables can affect the final $\mathrm{RuO}_{x}$ deposition. In both deposition cases, it can be noted that the deposition was (according to XPS analysis) primarily $\mathrm{RuO}_{2}$.

3.1. Effect of Methanol. Much has been written on the role of hole scavengers in the photocatalytic process, as their presence allows electrons to more easily participate in reductive photocatalysis by hindering electron-hole recombination. ${ }^{30}$ This can alter the speed of the reaction and even alter the favorability of certain reactions, making some interactions more or less likely. When studied in this work, the presence or absence of methanol had a definite, easily observed effect on the morphology of the photodeposited material, which was discernible to the naked eye as a difference in color at longer exposure times. When methanol was absent, the $\mathrm{RuO}_{x}$ formed into nanospheroidal, cauliflower-like particles during the photodeposition process, as seen in Figure 1 and Supporting Information Figure S2. Similar structures have been found in other $\mathrm{RuO}_{x}$ deposition processes. ${ }^{31}$ When methanol was present, the photodeposited $\mathrm{RuO}_{x}$ formed a fibrous, spongelike structure, as seen in Figure 4 and in Supporting Information Figure S5. These structures bear visual similarity to amorphous $\mathrm{RuO}_{2}$ structures that were created via other deposition methods, such as galvanostatic photodeposition, but these have not been linked to the presence of a hole scavenger. $^{32,33,33}$

The effects of isopropanol, ethanol, and thiol on the evaporative deposition of $\mathrm{RuCl}_{3}$ obtained sols have been previously investigated ${ }^{34}$ but this cannot explain the morphological differences we see here. Although some of the reported differences, such as faster deposition in the presence of a hole scavenger (2-propanol), are similar to results described in this work, they do not report observing a complete change in the morphology of the structures between the purely aqueous deposition and the hole scavenger-aided deposition. Furthermore, the deposition process described utilizes $\mathrm{RuCl}_{3}$, which has a different deposition pathway, and utilizes evaporative deposition of sols, which is completely different from the method outlined in this paper.

Figure 6 builds off the currently accepted photodeposition processes for similar materials and proposes a mechanism that

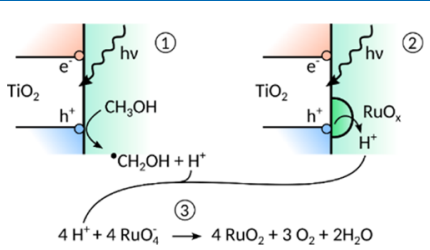

Figure 6. Photodeposition of $\mathrm{RuO}_{x}$ on $\mathrm{TiO}_{2}$ in the presence and in the absence of methanol: (1) photogenerated holes are scavenged by a methanol molecule, which oxidizes into $\mathrm{CH}_{2} \mathrm{OH}$ and a positively charged hydrogen ion; (3) four hydrogen ions and four perruthenate ions reduce onto $\mathrm{TiO}_{2}$ to form the $\mathrm{RuO}_{x}$. Once $\mathrm{RuO}_{x}$ exists on the surface, it itself becomes a catalytic site capable of scavenging holes and generating hydrogen ions (2), allowing for further deposition on the existing deposit through (3). Alternatively, in the absence of methanol, the dissociation of water (water splitting) on the surface of $\mathrm{TiO}_{2}$ in its anatase form provides an initial amount of positive hydrogen ions for reaction (3), according to the oxygen evolution reaction, $2 \mathrm{H}_{2} \mathrm{O} \rightarrow 4 \mathrm{H}^{+}+\mathrm{O}_{2}+4 \mathrm{e}^{-}$.

describes a probable cause for the structural difference observed between the photodeposition processes with and without methanol. Both photodeposition pathways ultimately rely on reaction (3), in which four hydrogen ions and four perruthenate $\left(\mathrm{RuO}_{4}\right)$ ions reduce onto $\mathrm{TiO}_{2}$ to form $\mathrm{RuO}_{2}{ }^{22}$ Though described as a one-step process here, this is actualy an energetically favorable two-step process. $^{35}$ This two-step reaction is what generates the $\mathrm{RuO}_{x}$ nanostructures and nanoparticles on the $\mathrm{TiO}_{2}$ surface. Further, this step primarily results in the deposition of $\mathrm{RuO}_{2}$, which is consistent with the 
XPS measurements. The difference in morphology, we posit, comes from how and where the hydrogen ions are generated.

When photodeposition is carried out in the presence of methanol, a photogenerated hole can be scavenged by a methanol molecule (1), which oxidizes into $\mathrm{CH}_{2} \mathrm{OH}$ and a positively charged hydrogen ion. This photocatalytic process has been observed previously, such as on platinum- $\mathrm{TiO}_{2}$ composite catalysts. ${ }^{36-38}$ Next, the previously described deposition of $\mathrm{RuO}_{x}$ (3) occurs, using these hydrogen ions. Once a deposit of ruthenium oxide has formed, it can also become a catalytic site for scavenging the holes that are photogenerated in $\mathrm{TiO}_{2}$ to generate hydrogen ions, (2), which leads to the formation of more $\mathrm{RuO}_{x}$ on the existing deposit. $^{39,40}$

At higher methanol concentrations, such as $10 \%$ by volume, we suggest that process (1) dominates as the hydrogen ion production mechanism, outcompeting process (2) and allowing process (3) to occur anywhere on the substrate, which leads to a broad distribution of ruthenium deposition sites. This, in turn, would lead to the thin, fibrous, spongy, and broadly distributed structure we see in the deposition, where methanol was present, seen in Figure 4, and in Supporting Information Figures S5 and S6, as a large number of active growth sites would be created across the substrate, and additional new growth sites could be created throughout the process without depleting the available methanol. This would also result in films that are not noticeably thicker even at longer deposition times, which is what we see in the edge-on images (Figures 4f and S6). This deposition process would only be limited by the amount of available methanol and by the photoactivity of the surface, which could be reduced as the $\mathrm{RuO}_{x}$ coverage increased.

In situations where no methanol is present, the hydrogen ions cannot come from process (1). In this scenario, the source of the initial four hydrogen ions can be through water splitting, which $\mathrm{TiO}_{2}$ is capable of. ${ }^{41,42}$ Once initial nucleation sites have formed, process (2) becomes the mechanism for creating additional $\mathrm{H}^{+}$and continues to deposit $\mathrm{RuO}_{x}$ on these initial growth sites through process (3). This would favor the growth of existing particles over new growth sites, which would lead to the very large particles seen in Figure 1 and in Supporting Information Figure S2.

Some support for this mechanism can be found in the results presented in Tilley et al., ${ }^{18}$ where the galvanostatic photodeposition of $\mathrm{RuO}_{x}$ onto amorphous titanium formed under different ALD conditions (hydrogen peroxide vs water precursors) resulted in very different deposition morphologies. One explanation presented by Tilley et al. is that the different ALD precursors caused the $\mathrm{TiO}_{2}$ films to have different nucleation and growth sites, which then in turn lead to very different $\mathrm{RuO}_{x}$ morphologies. This is similar to our own explanation, where the presence of a large quantity of methanol vastly increases the number of possible nucleation sites. This said, it should be noted that the experiment in Tilley et al. is distinct from ours-our deposition mechanism is purely photodeposition, our $\mathrm{TiO}_{2}$ substrate is in the anatase phase, and we vary the hole-scavenger concentration, rather than the substrate formation process. Nevertheless, their findings do help lend some support to our own.

Further, we can rule out other possible explanations for the morphology differences. If this structural difference was caused simply by the presence of a hole scavenger greatly speeding up the photodeposition process, then samples photoexposed in the presence of a hole scavenger for shorter times (such as samples F and G, shown in Supporting Information Figure S5, and sample $\mathrm{H}$, shown in Figure 4d,e) should show some similarity to the samples photoexposed without a hole scavenger for long time periods (such as sample A, Figure $1 \mathrm{a}-\mathrm{c})$. However, no such similarity was found, and beyond both samples showing signs of very small (approximately less than $10 \mathrm{~nm}$ in diameter) particles, there were no structures in samples A-D that were similar to structures found in samples E-G and vice-versa. Similarly, we can rule out the possibility that the methanol is simply causing uncontrolled chemical deposition of $\mathrm{RuO}_{x}$. As we did see a difference between these two regions in samples with exposure times above $5 \mathrm{~min}$ (samples E, F, and G), we can be certain that this remained a photodriven or photoassisted process, and that the formation of $\mathrm{RuO}_{x}$ structures was not solely the chemical deposition of the $\mathrm{RuO}_{x}$ because of the presence of methanol.

3.2. Effect of Photodeposition Time. Our results also confirm that both forms of this process (with and without methanol) are photodriven or photoassisted process. This is made clear when examining the data: A major difference can be seen between the exposed and unexposed areas of samples A-C and of samples E-G, with far less deposition present in the unexposed areas of these samples than in the exposed areas. Although some nonspecific growth did occur, there is still a massive degree of difference between the exposed and unexposed areas.

Additionally, we saw that the size and quantity of the deposited $\mathrm{RuO}_{x}$ could be manipulated by altering the deposition time, with longer deposition times, resulting in larger and more numerous deposits. For very short exposure times (sample D and sample $H$, shown in Figures $1 d$,e and $3 \mathrm{~d}, \mathrm{e}$, respectively), very little deposition occurred in the photoexposed areas, setting a lower bound on the exposure times necessary for successful deposition of larger nanoparticles and nanostructures at this illumination power: approximately $5 \mathrm{~min}$ at a power of $150 \mu \mathrm{W} / \mathrm{cm}^{2}$. When looking closer at the samples at shorter photodeposition times (e.g., Figure 1d,e, and Supporting Information Figure S2), a large quantity of small, sub-10 nm particles can be seen in the photoexposed areas. Similar small particles can also be seen when the deposition occurred in the presence of methanol (Figure 4b, Supporting Information Figure S5), therefore, depending what size of nanoparticle is desired, shorter deposition times on the order of less than 5 min may also be viable. As exposure time increased to $10,15,30$, and 45 $\mathrm{min}$, the fabricated structures were shown to grow larger in all cases (see Supporting Information Figures S2 and S3 for growth without methanol and Supporting Information Figures S5 and S6 for growth with methanol, both available online). The data in Table 2 support this general trend (with the exception of sample C), showing both increased particle size and coverage as exposure time increases. This is consistent with the explanation laid out in the previous section, where the generation of hydrogen is driven/accelerated by the photocatalysis of either water or methanol by the $\mathrm{TiO}_{2}$ and/or $\mathrm{RuO}_{x}$.

3.3. Effect of the $\mathrm{TiO}_{2}$ Phase. No growth was seen on the amorphous $\mathrm{TiO}_{2}$ substrates, demonstrating that the crystallinity of the samples is deeply important and should be taken into account and explicitly considered in this deposition process. The amorphous $\mathrm{TiO}_{2}$ samples, shown in Supporting Information Figure S5 and Supporting Information Figure S8, showed little or no photodeposition activity with either 
solution, even with a greatly extended photoexposure times of $90 \mathrm{~min}$, indicating that the reaction proceeds extremely slowly on amorphous $\mathrm{TiO}_{2}$, if at all, when compared with photodeposition on anatase $\mathrm{TiO}_{2}$. In contrast, photodeposition proceeded on the anatase $\mathrm{TiO}_{2}$ substrates shown in Figures 1 and 3 at shorter exposure times, becoming faintly discernible after only $5 \mathrm{~min}$ of photoexposure, seen in Figures 1d,e and 3e,f for samples $\mathrm{D}$ and $\mathrm{H}$, respectively. Possible reasons for this difference include amorphous $\mathrm{TiO}_{2}$, presenting fewer viable nucleation sites, such as the lack of grain boundaries and functional sites, and the difference in electrical properties between the two morphologies. Although there is also a band gap difference between the two phases, this was accounted for by changing the wavelength of the light used in the photodeposition process with the amorphous titanium samples. Further, the difference in photon flux between the anatase and amorphous samples was approximately 9\%. It should be noted that previous research using different deposition techniques, such as galvanostatic photodeposition ${ }^{18}$ or electrochemical anodization, ${ }^{23}$ have deposited $\mathrm{RuO}_{x}$ onto amorphous $\mathrm{TiO}_{2}$ substrates. This strongly suggests that the lack of deposition on the amorphous samples was also influenced by the known lower photocatalytic activity of amorphous, untreated $\mathrm{TiO}_{2}$. ${ }^{43}$

\section{CONCLUSIONS}

Our results have demonstrated the photodeposition of $\mathrm{RuO}_{x}$ onto thin $\mathrm{TiO}_{2}$ anatase films, set a lower bound of 5-15 min for the total photoexposure necessary to promote photodeposition of larger particles at an illumination of $150 \mu \mathrm{W} /$ $\mathrm{cm}^{2}$, briefly outlined the effects of different parameters that have an effect on the photodeposition process, demonstrated how the morphology can be dramatically altered via the addition of methanol, and provided a possible explanation for the different morphologies obtained by photodeposition in the presence and absence of a hole scavenger. The two parameters that caused the largest differences in the photodeposition process were the crystallinity of the $\mathrm{TiO}_{2}$ and the presence (or absence) of a hole scavenger while the photodeposition time primarily governed the size and density of the photodeposited nanostructures. The crystallinity of the $\mathrm{TiO}_{2}$ determined whether the photodeposition would proceed at all, with amorphous $\mathrm{TiO}_{2}$ proving unfavorable for the $\mathrm{RuO}_{x}$ photodeposition while the reaction proceeded readily on anatase $\mathrm{TiO}_{2}$.

The most significant and novel finding is how the presence/ absence of methanol had an evident effect on the morphology of the photodeposited $\mathrm{RuO}_{x}$. When present at a concentration of $10 \%$ in the deposition solution, fibrous sponge-like structures formed. When absent, cauliflower-like nanospheroids formed instead. Further study of the effect of methanol on the photodeposited structure is warranted, especially attempts to determine what methanol concentrations are needed to create hybrid morphologies. XPS analysis showed that the photodeposited $\mathrm{RuO}_{x}$ was primarily $\mathrm{RuO}_{2}$ in both deposition mechanisms, with the XPS results of the methanoldeposited sample, suggesting a higher proportional percentage of $\mathrm{RuO}_{2}$. We show that the deposition takes place only in the illuminated region of the sample, making this method suitable for deposition areas from a few millimeters in size to full wafers. The process is fast, works at room temperature, and involves no other high stress steps, making it compatible with wide range of different workflows.
Planned future work includes an investigation to determine the optimal catalytic loading and morphology (fibrous sponge vs nanospheres) for this deposition process. This would include investigating the effect of additional parameters such as postprocessing, and solution $\mathrm{pH}$, as well as exploring the deposition over a wider range of methanol concentrations, in a process similar to the work in Tossi et al. ${ }^{25}$ Ideally, this would also find a method to reduce the nonspecific deposition, potentially by reducing the concentration of the $\mathrm{KRuO}_{4}$ solution. This work could then be used to attempt to develop a submersible, self-contained water-splitting photodevice or explored with an eye toward other catalytic processes.

\section{MATERIALS AND METHODS}

5.1. Reagents and Materials. $\mathrm{KRuO}_{4}$ was purchased from Sigma-Aldrich. Methanol was acquired from Honeywell. Silicon substrates were purchased from Siegert Wafer.

5.2. Substrate Formation. Anatase and amorphous $\mathrm{TiO}_{2}$ substrates were grown via ALD deposition on the polished surface of a silicon wafer in Beneq TFS-500 ALD at $250{ }^{\circ} \mathrm{C}$ for anatase and $150{ }^{\circ} \mathrm{C}$ for amorphous. The $\mathrm{TiCl}_{4}$ and $\mathrm{H}_{2} \mathrm{O}$ were used as the precursor chemicals for both substrates, with $\mathrm{TiCl}_{4}$ being set at a pulse length of $200 \mathrm{~ms}, \mathrm{H}_{2} \mathrm{O}$ being set at a pulse length of $150 \mathrm{~ms}$, and both precursors were set to a flow rate of $200 \mathrm{sccm}$. The deposition was carried out over 1000 cycles, and the final thickness of the films was confirmed to be approximately $45 \mathrm{~nm}$ using a standard ellipsometer.

5.3. Precursor Solutions. A $1 \mathrm{mM}$ stock solution of $\mathrm{KRuO}_{4}$ was formed by adding $2 \mathrm{mg}$ of powdered $\mathrm{KRuO}_{4}$ to 10 $\mathrm{mL}$ of DI water and stirring vigorously. The solution was then purged with nitrogen to prolong its lifespan. Although the original method ${ }^{22}$ does not explicitly list a hole scavenger as part of the photodeposition process, other papers mention the necessity of a hole scavenger when discussing similar deposition techniques, such as galvanostatic photodeposition. ${ }^{18}$ In order to clarify the effect of a hole scavenger on photocatalysis, a second stock solution was created by adding $200 \mu \mathrm{L}$ of methanol to $1.8 \mathrm{~mL}$ of the stock $1 \mathrm{mM} \mathrm{KRuO}_{4}$ to create a solution that was $10 \%$ methanol by volume.

5.4. Photodeposition. Sample substrates were rinsed with ethanol, isopropanol, and water, and then blown dry and placed faceup in the sample holder. A $100 \mu \mathrm{L}$ droplet of the precursor solution was placed on the sample area, and then the sample was covered by a cover slip held up by two silicon shims to create a cavity. Afterward, the photomask was placed over the sample, and the sample was exposed for varying deposition times, as outlined previously in Table 1.

Light was emitted by a Zahner TLS03 tuneable light source, then reflected downward using a mirror. It passed through a photomask and a thin glass coverslip before striking the sample with a measured power of $150 \mu \mathrm{W} / \mathrm{cm}^{2}$ at the sample location. In order to ensure that the photon energy was greater than the band gap in all materials, a $345 \mathrm{~nm}$ wavelength was used for anatase samples, and a $315 \mathrm{~nm}$ wavelength was used for amorphous titanium samples. Because of this, the amorphous samples exposed to $315 \mathrm{~nm}$ light experienced a photon flux approximately $9 \%$ lower than the anatase samples, but this difference was more than accounted for with the increase in the photoexposure time.

A schematic of the exposure setup is shown in Figure 7.

Afterward, the samples were removed, rinsed gently in DI water, and blown dry with compressed nitrogen. 


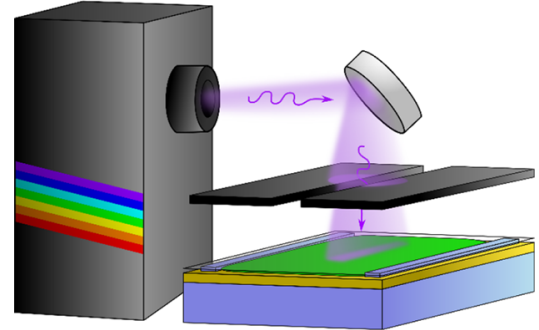

Figure 7. Diagram of the exposure setup. UV light is reflected down onto the sample surface after passing through a photomask. The $\mathrm{KRuO}_{4}$ precursor solution is kept on the sample surface via a glass coverslip, held up by two silicon shims.

5.5. Sample Characterization. Surface imaging was carried out by a Zeiss Supra 40 field-emission scanning electron microscope (SEM) using the Inlens primary electron detector. Edge images were taken by bisecting a sample to create an exposed edge inside the photoexposure region and then imaged in SEM at an $80^{\circ}$ angle using same SEM. EDX measurements were taken using an EDAX probe in a Helios 600 Focused Ion Beam system with a current of $2.7 \mathrm{nA}$ and a beam power of $10 \mathrm{keV}$. XPS analysis was carried out using a Kratos Axis Ultra ESCA system. AFM measurements were carried out with Dimension Icon AFM by Bruker. Analysis of AFM measurements was carried out using Gwyddion analysis software.

5.6. Safety. Standard laboratory practices apply. PPE should include nitrile/latex gloves, protective eyewear, and a well-ventilated fume hood or other chemical preparation environment. The potassium perruthenate, as purchased, is a very fine powder, which should be taken into account to prevent inhalation, ingestion, or exposure to eyes. Please consult the MSDS for additional information.

\section{ASSOCIATED CONTENT}

\section{(s) Supporting Information}

The Supporting Information is available free of charge at https://pubs.acs.org/doi/10.1021/acsomega.9b04077.

Visual comparison of two representative samples; additional photodeposition images for deposition with and without methanol at different times; XPS of the bare $\mathrm{TiO}_{2}$ substrate; and amorphous $\mathrm{TiO}_{2}$ photodeposition micrographs (PDF)

\section{AUTHOR INFORMATION}

\section{Corresponding Author}

Erich Michael See - Department of Electronics and Nanoengineering, Aalto University, Espoo 02150, Finland; ๑ orcid.org/0000-0003-2418-4580; Email: erich.see@ aalto.fi, serich@vt.edu

\section{Authors}

Camilla Tossi - Department of Electronics and Nanoengineering, Aalto University, Espoo 02150, Finland; (1) orcid.org/0000-0002-0450-6995

Lassi Hällström - Department of Electronics and Nanoengineering, Aalto University, Espoo 02150, Finland; (1) orcid.org/0000-0003-2592-2848

Ilkka Tittonen - Department of Electronics and Nanoengineering, Aalto University, Espoo 02150, Finland; ○ orcid.org/0000-0002-2985-9789
Complete contact information is available at:

https://pubs.acs.org/10.1021/acsomega.9b04077

Notes

The authors declare no competing financial interest.

\section{ACKNOWLEDGMENTS}

The authors acknowledge financial support from the Academy of Finland projects 285972 and 319018. C.T. acknowledges funding from the Vilho, Yrjö ja Kalle Väisälä Foundation grant issued by the Finnish Academy of Arts and Sciences, and L.H. the funding from the Aalto University ELEC Doctoral School. The present work was conducted in the Micronova Nanofabrication Center at Aalto University. We would also like to acknowledge the Academy of Finland Flagship Programme (320167, PREIN). We would also like to thank Jouko Lahtinen for providing the XPS measurements.

\section{REFERENCES}

(1) Prakash, J.; Sun, S.; Swart, H. C.; Gupta, R. K. Noble MetalsTiO2 Nanocomposites: From Fundamental Mechanisms to Photocatalysis, Surface Enhanced Raman Scattering and Antibacterial Applications. Appl. Mater. Today 2018, 11, 82-135.

(2) Anonymous. N. I. for Occupational Safety and Health. Current Intelligence Bulletin 63: Occupational Exposure to Titanium Dioxide, 2011.; N. I. for Occupational Safety and Health, Current Intelligence Bulletin 63: Occupational Exposure to Titanium Dioxide, 2011.

(3) Hernández-Alonso, M. D.; Fresno, F.; Suárez, S.; Coronado, J. M. Development of Alternative Photocatalysts to TiO2: Challenges and Opportunities. Energy Environ. Sci. 2009, 2, 1231-1257.

(4) Li, Z.; Luo, W.; Zhang, M.; Feng, J.; Zou, Z. Photoelectrochemical Cells for Solar Hydrogen Production: Current State of Promising Photoelectrodes, Methods to Improve their Properties, and Outlook. Energy Environ. Sci. 2013, 6, 347-370.

(5) Nowotny, J. Titanium Dioxide-Based Semiconductors for SolarDriven Environmentally Friendly Applications: Impact of Point Defects on Performance. Energy Environ. Sci. 2008, 1, 565-572.

(6) Coronado, J. M.; Fresno, F.; Hernández-Alonso, M. D.; Portela, R. Design of Advanced Photocatalytic Materials for Energy and Environmental Applications; Springer, 2013; pp 39-48.

(7) Fujishima, A.; Zhang, X.; Tryk, D. TiO2 Photocatalysis and Related Surface Phenomena. Surf. Sci. Rep. 2008, 63, 515-582.

(8) Di Paola, A.; García-López, E.; Marcì, G.; Palmisano, L. A Survey of Photocatalytic Materials for Environmental Remediation. J. Hazard. Mater. 2012, 211-212, 3-29.

(9) Luca, V.; Djajanti, S.; Howe, R. F. Structural and Electronic Properties of Sol-Gel Titanium Oxides Studied by X-Ray Absorption Spectroscopy. J. Phys. Chem. B 1998, 102, 10650-10657.

(10) Kudo, A.; Miseki, Y. Heterogeneous Photocatalyst Materials for Water Splitting. Chem. Soc. Rev. 2009, 38, 253-278.

(11) Li, C.; Zhang, S.; Zhang, B.; Su, D.; He, S.; Zhao, Y.; Liu, J.; Wang, F.; Wei, M.; Evans, D. G.; et al. Photohole-Oxidation-Assisted Anchoring of Ultra-Small $\mathrm{Ru}$ Clusters Onto $\mathrm{TiO} 2$ with Excellent Catalytic Activity and Stability. J. Mater. Chem. A 2013, 1, 24612467.

(12) Ran, J.; Zhang, J.; Yu, J.; Jaroniec, M.; Qiao, S. Z. EarthAbundant Cocatalysts for Semiconductor-Based Photocatalytic Water Splitting. Chem. Soc. Rev. 2014, 43, 7787-7812.

(13) Yang, J.; Wang, D.; Han, H.; Li, C. Roles of Cocatalysts in Photocatalysis and Photoelectrocatalysis. Acc. Chem. Res. 2013, 46, $1900-1909$.

(14) Gao, P.; Yang, L.; Xiao, S.; Wang, L.; Guo, W.; Lu, J. Effect of $\mathrm{Ru}, \mathrm{Rh}, \mathrm{Mo}$, and $\mathrm{Pd}$ Adsorption on the Electronic and Optical Properties of Anatase $\mathrm{TiO}_{2}(101)$ : A DFT Investigation. Materials 2019, 12, 814.

(15) Kang, J.-G.; Sohn, Y. Interfacial Nature of Ag Nanoparticles Supported on TiO2 Photocatalysts. J. Mater. Sci. 2012, 47, 824-832. 
(16) Zhang, P.; Wang, T.; Gong, J. Mechanistic Understanding of the Plasmonic Enhancement for Solar Water Splitting. Adv. Mater. 2015, 27, 5328-5342.

(17) Sobczynski, A.; Jakubowska, T.; Zielinski, S. Hydrogen Photoevolution from Water-Methanol on $\mathrm{Ru} / \mathrm{TiO} 2$. Monatsh. Chem. 1989, 120, 101-109.

(18) Tilley, S. D.; Schreier, M.; Azevedo, J.; Stefik, M.; Graetzel, M. Ruthenium Oxide Hydrogen Evolution Catalysis on Composite Cuprous Oxide Water-Splitting Photocathodes. Adv. Funct. Mater. 2014, 24, 303-311.

(19) Uddin, M. T.; Babot, O.; Thomas, L.; Olivier, C.; Redaelli, M.; D’Arienzo, M.; Morazzoni, F.; Jaegermann, W.; Rockstroh, N.; Junge, H.; et al. New Insights into the Photocatalytic Properties of RuO2/ $\mathrm{TiO} 2$ Mesoporous Heterostructures for Hydrogen Production and Organic Pollutant Photodecomposition. J. Phys. Chem. C 2015, 119, 7006-7015.

(20) Bahri, M.; Dembélé, K.; Sassoye, C.; Debecker, D. P.; Moldovan, S.; Gay, A. S.; Hirlimann, C.; Sanchez, C.; Ersen, O. In Situ Insight into the Unconventional Ruthenium Catalyzed Growth of Carbon Nanostructures. Nanoscale 2018, 10, 14957-14965.

(21) Tojo, G.; Fernández, M. Ruthenium Tetroxide and Other Ruthenium Compounds. In Oxidation of Primary Alcohols to Carboxylic Acids; Springer, 2007; pp 61-78.

(22) Mills, A.; Duckmanton, P. A.; Reglinski, J. A Simple, Novel Method for Preparing an Effective Water Oxidation Catalyst. Chem. Commun. 2010, 46, 2397-2398.

(23) Shin, S.; Kim, K.; Choi, J. Fabrication of Ruthenium-Doped $\mathrm{TiO} 2$ Electrodes by One-Step Anodization for Electrolysis Applications. Electrochem. Commun. 2013, 36, 88-91.

(24) Sungbom, C.; Kawai, M.; Tanaka, K. XPS Studies of the Platinum Species Photodeposited on Titania from Aqueous Chloroplatinic Acid. Bull. Chem. Soc. Jpn. 1984, 57, 871-872.

(25) Tossi, C.; Hällström, L.; Selin, J.; Vaelma, M.; See, E.; Lahtinen, J.; Tittonen, I. Size- and Density-Controlled Photodeposition of Metallic Platinum Nanoparticles on Titanium Dioxide for Photocatalytic Applications. J. Mater. Chem. A 2019, 7, 14519-14525.

(26) Lee, J.; Choi, W. Photocatalytic Reactivity of Surface Platinized TiO2: Substrate Specificity and the Effect of Pt Oxidation State. J. Phys. Chem. B 2005, 109, 7399-7406.

(27) Schneider, J.; Bahnemann, D. W. Undesired Role of Sacrificial Reagents in Photocatalysis. J. Phys. Chem. Lett. 2013, 4, 3479-3483.

(28) Müller, A.; Peglow, S.; Karnahl, M.; Kruth, A.; Junge, H.; Brüser, V.; Scheu, C. Morphology, Optical Properties and Photocatalytic Activity of Photo-and Plasma-Deposited $\mathrm{Au}$ and $\mathrm{Au} / \mathrm{Ag}$ Core/Shell Nanoparticles on Titania Layers. Nanomaterials 2018, 8, 502.

(29) Morgan, D. J. Resolving Ruthenium: XPS Studies of Common Ruthenium Materials. Surf. Interface Anal. 2015, 47, 1072-1079.

(30) Fernando, J. F. S.; Shortell, M. P.; Noble, C. J.; Harmer, J. R.; Jaatinen, E. A.; Waclawik, E. R. Controlling Au Photodeposition on Large ZnO Nanoparticles. ACS Appl. Mater. Interfaces 2016, 8, $14271-14283$.

(31) Patake, V. D.; Lokhande, C. D.; Joo, O. S. Electrodeposited Ruthenium Oxide Thin Films for Supercapacitor: Effect of Surface Treatments. Appl. Surf. Sci. 2009, 255, 4192-4196.

(32) Gujar, T. P.; Shinde, V. R.; Lokhande, C. D.; Kim, W.-Y.; Jung, K.-D.; Joo, O.-S. Spray Deposited Amorphous RuO2 for an Effective use in Electrochemical Supercapacitor. Electrochem. Commun. 2007, 9, 504-510.

(33) Hu, C.-C.; Chang, K.-H. Cyclic Voltammetric Deposition of Hydrous Ruthenium Oxide for Electrochemical Capacitors: Effects of Codepositing Iridium Oxide. Electrochim. Acta 2000, 45, 2685-2696.

(34) Panic, V.; Dekanski, A.; Milonjic, S.; Atanasoski, R.; Nikolic, B. The Effect of the Presence of Alcohol in the Dispersing Phase of Oxide Sols on the Properties of $\mathrm{RuO} 2-\mathrm{TiO} 2 / \mathrm{Ti}$ Anodes obtained by the Sol-Gel Procedure. J. Serb. Chem. Soc. 2000, 65, 649-660.

(35) Povar, I.; Spinu, O. Ruthenium Redox Equilibria 3. Pourbaix Diagrams for the Systems $\mathrm{Ru}-\mathrm{H} 2 \mathrm{O}$ and $\mathrm{Ru}-\mathrm{Cl}-\mathrm{H} 2 \mathrm{O}$. Int. J. Electrochem 2016, 6, 145-153.
(36) Berr, M. J.; Wagner, P.; Fischbach, S.; Vaneski, A.; Schneider, J.; Susha, A. S.; Rogach, A. L.; Jäckel, F.; Feldmann, J. Hole Scavenger Redox Potentials Determine Quantum Efficiency and Stability of PtDecorated CdS Nanorods for Photocatalytic Hydrogen Generation. Appl. Phys. Lett. 2012, 100, 223903.

(37) Ahmed, L. M.; Ivanova, I.; Hussein, F. H.; Bahnemann, D. W. Role of Platinum Deposited on $\mathrm{TiO} 2$ in Photocatalytic Methanol Oxidation and Dehydrogenation Reactions. Int. J. Photoenergy 2014, 2014, 1 .

(38) Guzman, F.; Chuang, S. S. C.; Yang, C. Role of Methanol Sacrificing Reagent in the Photocatalytic Evolution of Hydrogen. Ind. Eng. Chem. Res. 2013, 52, 61-65.

(39) Blondeel, G.; Harriman, A.; Porter, G.; Urwin, D.; Kiwi, J. Design, Preparation and Characterization of Ruthenium Dioxide/ Titanium Dioxide Catalytic Surfaces Active in Photooxidation of Water. J. Phys. Chem. 1983, 87, 2629-2636.

(40) Kleiman-Shwarsctein, A.; Laursen, A. B.; Cavalca, F.; Tang, W.; Dahl, S.; Chorkendorff, I. A General Route for RuO2 Deposition on Metal Oxides from RuO4. Chem. Commun. 2012, 48, 967-969.

(41) Nasikhudin; Diantoro, M.; Kusumaatmaja, A.; Triyana, K. Study on Photocatalytic Properties of $\mathrm{TiO} 2$ Nanoparticle in various pH Condition. J. Phys.: Conf. Ser. 2018, 1011, 012069.

(42) Bharti, B.; Kumar, S.; Lee, H.; Kumar, R. Formation of Oxygen Vacancies and $\mathrm{Ti} 3+$ State in $\mathrm{TiO} 2$ Thin Film and Enhanced Optical Properties by Air Plasma Treatment. Sci. Rep. 2016, 6, 32355.

(43) Li, P.-Y.; Liu, H.-W.; Chen, T.-H.; Chang, C.-H.; Lu, Y.-S.; Liu, D.-S. Characterization of an Amorphous Titanium Oxide Film Deposited Onto a Nano-Textured Fluorination Surface. Materials 2016, 9, 429. 